\title{
A PSICOLOGIA SOCIAL DO TRABALHO \\ COMO CAMPO DE PRÁTICAS, SABERES E RESISTÊNCIAS
}

\author{
LA PSICOLOGÍA SOCIAL DEL TRABAJO \\ COMO CAMPO DE PRÁCTICAS, SABERES $\Upsilon$ RESISTENCIAS
}

THE SOCIAL WORK PSYCHOLOGY AS A FIELD

OF PRACTICES, KNOWLEDGE AND RESISTANCES

\section{Maristela de Souza Pereira ${ }^{1}$}

${ }^{1}$ Universidade Federal de Uberlândia, Uberlândia/MG, Brasil

\section{Resenha de}

Coutinho, M. C., Bernardo, M. H., \& Sato, L. (Orgs.). (2017). Psicologia Social do Trabalho. Petrópolis, RJ: Vozes.

O livro ora apresentado representa um esforço de sistematização sobre a Psicologia Social do Trabalho (PST), e marca de certo modo um reconhecimento mais formalizado sobre esse campo. Os autores apontam influências teóricas, resgatam experiências empíricas e fazem uma análise dos contextos sociais e históricos em que estas se deram, realizando uma tessitura que revela a constituição de um campo de saberes e de práticas que tem sido construído nas últimas décadas e que, embora englobe uma multiplicidade de perspectivas, possui princípios e contornos bem nítidos. Nesse sentido, se retomarmos Gergen (2008), um texto clássico na análise da Psicologia Social enquanto empreendimento histórico, veremos que as organizadoras do livro demonstram de forma inequívoca que o conhecimento não pode ser acumulado, ao contrário, é sempre uma construção. Assim, expõem-se as ligações entre as problemáticas que foram se apresentando em diferentes momentos, as práticas científicas e interventivas que aquelas ensejaram, as teorias que as sustentaram, situando as relações entre essas faces, de modo a ser talhada uma área de atuação profissional de grande relevância e atualidade para os psicólogos sociais.

A obra permite compreender os princípios da Psicologia Social do Trabalho, pautados na leitura crítica da realidade, na interdisciplinaridade, na ênfase no conhecimento e experiência dos trabalhadores, em uma perspectiva contra-hegemônica e não exploratória desses, na assunção da dimensão política como inseparável da dimensão científica, na constatação da relação fulcral entre a subjetividade e os aspectos objetivos e materiais de existência, na indissociabilidade entre pesquisa, prática e intervenção, na horizontalidade das relações entre sujeitos pesquisadores e sujeitos trabalhadores, e na busca pela transformação social e das condições de trabalho. Esses aspectos evidenciam que se trata de uma modalidade de Psicologia Social emoldurada nos contornos das chamadas perspectivas sociológicas dessa disciplina. Tais marcadores apontam de modo inexorável as profundas diferenças entre esta abordagem e a Psicologia Organizacional, as quais, embora assinaladas em obras anteriores das organizadoras ${ }^{1}$, ficam aqui evidentes e traduzem de 
forma límpida que se tratam de duas perspectivas antagônicas no campo do estudo e das ações relacionadas ao mundo do trabalho, tal qual elucidado por Bourdieu (1994).

O livro está organizado em sete capítulos, escritos por diversos autores, ligados entre si por tomarem parte no mesmo Grupo de Trabalho da Associação Nacional de Pesquisa e Pós-graduação em Psicologia (ANPEPP)² e por visadas que buscam problematizar o trabalho, os aspectos que o circundam, e construir leituras teóricas ancoradas em pesquisas empíricas e intervenções em diversos de seus cenários. Cabe destacar, que embora sejam capítulos independentes entre si, guardam uma coerência na escolha das temáticas, havendo um encadeamento de ideias em sua organização, a qual apresenta a conjuntura de surgimento da área, seus pressupostos teóricos e metodológicos, algumas categorias-chave para seus estudos, além de exemplos de intervenções, finalizando com uma reflexão sobre aspectos e temáticas que ainda requerem investigação. Outro ponto a se ressaltar é a existência de uma conexão entre os diferentes capítulos e discussões, feita de modo original através das notas de rodapé, que ora vão retomando questões já apresentadas, ora vão antecipando aprofundamentos que estão por vir.

O primeiro capítulo, escrito pelas três organizadoras da obra, traz considerações sobre o percurso trilhado pela Psicologia Social do Trabalho, apontando que este não se deu a partir de um projeto preexistente ou de uma proposta pré-definida, e sim configurou-se a partir das demandas que foram se apresentando aos psicólogos que se propunham a investigar as questões do trabalho, sob um olhar social. Nesse texto introdutório, assume-se a centralidade da categoria trabalho e demarca-se o lócus de seus esforços investigativos: os contextos reais de trabalho, nos quais se intercruzam as vivências singulares dos sujeitos e os processos macrossociais que as determinam.

Tendo em conta que o contexto histórico não é apenas o pano de fundo, mas fundamentalmente estabelece condições de possibilidade para a constituição dos seres e das instituições, Vera Navarro, Regina Maciel e Tereza Matos analisam no segundo capítulo o processo de desenvolvimento do capitalismo no Brasil, transitando por suas diferentes fases e apresentando balizadores importantes para pensarmos sobre o momento atual e sobre como as configurações contemporâneas do trabalho foram sendo viabilizadas através de escolhas originadas no plano político e materializadas nas relações produtivas. Assim, mais do que uma descrição histórica, o que elas oferecem é uma narrativa sobre as circunstâncias nas quais os processos de trabalho foram sendo moldados em nosso país, elucidando como os acontecimentos sociais se desdobram no cotidiano e podem influenciar de forma dramática as condições de vida dos sujeitos, e também o desenvolvimento das disciplinas científicas, tal qual nos lembra Farr (1996).

Ainda de acordo com essa perspectiva, que compreende a história da ciência como fundada na história dos cenários e situações em que a ciência se desenvolve, Egeu Esteves, Marcia Hespanhol e Leny Sato revisitam no capítulo 3 acontecimentos, estudos e autores que ajudaram a conformar a PST enquanto área, situando as fontes do pensamento e das práticas que lhe modelaram. Note-se que não se trata aqui de apontar antecedentes, mas de tomar em consideração como eventos separados no tempo e espaço, com diferentes protagonistas, ensejaram experiências que, ao serem vivenciadas e compartilhadas, foram descortinando novos modos de se olhar, pensar e agir nos âmbitos acadêmicos e de atuação profissional sobre a questão do trabalho. Dois fenômenos de grande relevância nesse processo foram o surgimento do campo Saúde do Trabalhador e o desenvolvimento da Economia Solidária, ambos gestados por lutas coletivas e sedimentados por políticas 
públicas, que pavimentaram novos espaços de atuação para os psicólogos interessados em perspectivas contra-hegemônicas vinculadas à temática do trabalho.

No Capítulo 4, Maria Chalfin e Fábio de Oliveira apresentam algumas categorias teóricas que têm se constituído como referência para diversos estudos em PST, a saber: as práticas cotidianas, os processos de significação e as identidades. Tais categorias transmutam-se de um sentido pronto e acabado, para assumirem o papel de ferramentas teóricas, que oferecem parâmetros para as investigações, mas sem aprisionar os sentidos que delas podem surgir. Segundo essa ótica, focalizar as práticas cotidianas no trabalho possibilita um giro no olhar dos pesquisadores, que passam a buscar nas minúcias, no miúdo da vida, as vivências que expressam de modo contundente as teias do poder, da exploração e da opressão, mas também a inventividade, as astúcias e as resistências dos trabalhadores e trabalhadoras, que configuram o que Michel de Certeau (2009) designa por táticas ou artes do fraco. Já os processos de significação, ainda que sob essa terminologia estejam abrigadas leituras diversas, remetem ao caráter imbricado de práticas e sentidos, posto que a configuração de subjetividades e a produção de sentidos não são descoladas das vivências que as originam. Estas vivências, por sua vez, têm lugar em planos materiais específicos, em situações que se objetivam nas práticas e que promovem interpretações por parte dos agentes que nelas tomam parte. Quanto às identidades, o uso desse termo no plural não é fortuito, visto que traduz uma miríade de compreensões sobre os processos identitários. No entanto, trata-se de uma categoria da maior importância, para se pensar o lugar ocupado pelo trabalho na constituição dos sujeitos, tanto em sua dimensão subjetiva, quanto objetiva. Como salientam os autores, esses três fenômenos estão fundamentalmente articulados, uma vez que práticas produzem sentidos, os quais guiam as práticas, e ambos viabilizam identidades, produzidas nas ações das pessoas sobre o mundo e nas leituras que vão construindo sobre essas ações.

No capítulo seguinte, Marcelo Ribeiro, Fábio de Oliveira, Márcia Hespanhol e Vera Navarro assumem que não há pesquisa que não seja de algum modo intervenção e que toda intervenção traz em si o gérmen de uma investigação. Nesse capítulo, é trabalhada de forma mais intensa a dimensão ético-política do trabalho do pesquisador, ao se reconhecer os inevitáveis impactos da ciência sobre as realidades que essa intenta conhecer. Colocam-se então alguns objetivos que devem nortear as práticas investigativas em Psicologia Social do Trabalho, como a denúncia de condições de trabalho opressoras e adoecedoras, a desmistificação de estereótipos sobre sujeitos e atividades a que se dedicam, a identificação de problemas e desafios colocados pelo trabalho para os trabalhadores, e o afrontamento das relações desiguais e de exploração a que as pessoas são submetidas no cenário capitalista neoliberal. Os autores lançam ainda reflexões pungentes sobre a atuação dos psicólogos, ao lembrarem que se não trabalhamos em prol da erradicação das desigualdades, fatalmente estaremos contribuindo para sua manutenção, tal qual discute Prilleltensky (1994). Certamente essa não é uma proposição nova. Já na década de 70, Martín-Baró alertava os psicólogos sobre a necessidade de assumirem a perspectiva dos dominados e confrontar o saber psicológico com as problemáticas vivenciadas por esses, colocando-se a serviço das transformações das situações objetivas que causam sofrimento, miséria, doença e morte das populações (Martín-Baró, 1997). Quase 50 anos depois, temos diversos exemplos concretos de ações guiadas por esse horizonte, alguns apresentados na obra aqui discutida.

O Capítulo 6 traz importantes reflexões sobre um tema ainda pouco explorado pelos psicólogos, o trabalho rural. Rosimeire Scopinho recorda que os trabalhadores do campo 
têm grande importância para a economia, embora historicamente tenham recebido pouca visibilidade política e social, e aponta para a importância de nos debruçarmos sobre esse universo, com vistas a compreender os modos de vida, as subjetividades, as necessidades e formas de satisfazê-las que essa população tem encontrado. Retoma ainda as diversas lutas travadas nesse cenário, tanto pelo direito à terra quanto pelo direito à vida digna, à segurança, ao enraizamento, ao reconhecimento de suas formas de sociabilidade e seus modos de ser ativo no mundo.

No último capítulo, Leny Sato reflete sobre o fato de que a PST teve por objetivo inicial o trabalho urbano, formal, industrial e regulado, dedicando-se a estudar as conformações de trabalho sob a forma do emprego. A autora chama a atenção para a necessidade de voltarmos nossos esforços investigativos também sobre as formas de trabalho informal, marginal e ilegal. Desse modo, aponta temáticas que ainda carecem de estudos e desafios que se colocam para o futuro do campo.

Diversos dos exemplos e iniciativas analisados ao longo do livro estão relacionados à região Sudeste do país, pois decorrem das experiências dos autores, ambientadas em sua grande maioria nessa área geográfica. Nota-se que se coloca aqui outro desafio, o de ampliarmos a visibilidade das práticas em PST que acontecem em outras localidades e que podem apresentar diferenças regionais importantes.

Diante do exposto, vemos que se trata de uma obra de grande relevância, que cumpre importante papel no sentido de dar materialidade para o campo da Psicologia Social do Trabalho, ao mesmo tempo em que apresenta seus fundamentos, premissas, características e, principalmente, coloca reflexões críticas bem sedimentadas com relação ao fazer do psicólogo nos contextos de trabalho. Não é possível passar incólume por essa leitura, que traz, a todo momento, ponderações sobre o compromisso ético e político a ser assumido por nós, como membros dessa categoria profissional. Que esse alerta possa encontrar eco nas nossas práticas, direcionando-as para propósitos libertários e de enfrentamento das investidas neoliberais, de modo a contribuirmos para a emancipação dos trabalhadores e trabalhadoras, aí incluídos/as nós mesmos/as, ao invés de reproduzirmos desigualdades e modos novos, ou já consagrados, de exploração.

\section{Notas}

1 A título de ilustração, ver Sato (2003) e Bernardo, Oliveira, Souza e Sousa (2017).

2 GT Trabalho e Processos Organizativos na Contemporaneidade. 


\section{Referências}

Bernardo, M. H., Oliveira, F., Souza, H. A., \& Sousa, C. C. (2017). Linhas paralelas: as distintas aproximações da Psicologia em relação ao trabalho. Estudos de Psicologia, 34(1), 15-24.

Bourdieu, P. (1994). O campo científico. In R. Ortiz (Org.), Pierre Bourdieu (pp. 122-155). São Paulo: Ática.

Certeau, M. (2009). A invenção do cotidiano: Artes de fazer. Petrópolis, RJ: Vozes.

Coutinho, M. C., Bernardo, M. H., \& Sato, L. (Orgs.). (2017). Psicologia Social do Trabalho. Petrópolis, RJ: Vozes.

Farr, R. M. (1996). As raízes da Psicologia Social Moderna. Petrópolis, RJ: Vozes.

Gergen, K. J. (2008). A Psicologia Social como História. Psicologia छ Sociedade, 20(3), $475-484$.

Martín-Baró, I. (1997). O papel do Psicólogo. Estudos de Psicologia, 2(1), 7-27.

Prilleltensky, I. (1994). Morals and Politics of Psychology: Psychological Discourse and the Status Quo. Albany, NY: State University of New York Press.

Sato, L. (2003). Psicologia, Saúde e Trabalho: distintas construções dos objetos "Trabalho" e "Organizações". In Z. A. Trindade \& A. N. Andrade (Orgs.), Psicologia e Saúde: um campo em construção (pp. 167-178). São Paulo: Casa do Psicólogo.

\section{MARISTELA DE SOUZA PEREIRA \\ https://orcid.org/0000-0001-6520-079X}

Docente do Instituto de Psicologia da Universidade Federal de Uberlândia.

Membro do Núcleo de Psicologia Social e da Saúde.

Endereço institucional: Av. Pará, 720 - Bloco 2C, sala 34, Campus Umuarama

- Universidade Federal de Uberlândia - Uberlândia/MG (38.400-902).

E-mail: maristela.ufu@gmail.com

\begin{tabular}{|l|l|}
\hline \multirow{3}{*}{ Histórico } & $\begin{array}{l}\text { Submissão: 08/03/2018 } \\
\text { Revisão: 26/06/2019 } \\
\text { Aceite: 10/07/2019 }\end{array}$ \\
\hline
\end{tabular}

